\title{
Identifikasi Kedipan Mata dengan Menggunakan Sensor Electroencephalography dan Metode K-Nearest Neighbour
}

\author{
Swadexi Istiqphara, Rudi Uswarman, dan Uri Arta Ramadhani \\ Institut Teknologi Sumatera \\ Lampung Selatan, Indonesia \\ Corresponding author's e-mail: swadexi.istiqphara@el.itera.ac.id
}

\begin{abstract}
Abstrak - Pada paper ini membahas tentang pendeteksian kedipan mata dengan menggunakan metode KNearest Neighbour dan Perangkat sensor gelombang otak (Electroencephalography/EEG). EEG atau Sensor gelombang otak merupakan sensor yang terdiri dari elektroda yang berfungsi untuk mendeteksi sinyal-sinyal listrik pada permukaan kulit kepala. Sinyal-sinyal listrik dihasilkan oleh gelombang otak saat tubuh melakukan aktifitas fisik, seperti mengedipkan mata, menggerakan tangan, kondisi tidur dan juga saat emosi. Pada EEG, elektroda yang digunakan sebaiknya lebih dari satu buah, hal ini untuk mendeteksi perubahan sinyal listrik dibeberapa bagian kepala sehingga dapat meningkatkan jenis aktifitas tubuh yang dapat diidentifikasi. Luaran EEG merupakan hasil pembacaan listrik yang dikonversi kedalam nilai ADC, sehingga masih membutuhkan pemrosesan selanjutnya agar dapat digunakan untuk mendeteksi gerakan. Pada paper ini digunakan metode KNearest Neighbour dengan dua teknik pemrosesan data untuk memproses data yang dihasilkan oleh elektroda untuk mendeteksi berkedip atau tidak. Hasil yang diperoleh menunjukan KNN \#2 memiliki performa yang lebih baik dibandingkan metode KNN \#1 baik dalam akurasi maupun kecepatan.
\end{abstract}

Kata kunci: EEG, sensor otak, gelombang otak, metode KNN, kedipan EEG

\section{Pendahuluan}

Penelitian tentang sensor otak sudah dilakukan oleh banyak peneliti sejak lama. Hal ini menarik dan cukup menantang bagi para peneliti untuk mengetahui hubungan antara gelombang otak dengan aktifitas manusia seperti merespon lingkungan, menggerakan anggota badan dan menggerakan mata. Penelitian tentang hubungan antara gelombang otak dengan aktifitas manusia ini kedepannya akan dimanfaatkan untuk banyak hal sebagai contoh untuk menggerakan robot, menggerakan aktuator dan juga menggerakan virtual reality.

Sensor otak merupakan perangkat elektronik yang digunakan untuk mengukur energi listrik yang ada di otak manusia. Perangkat ini menggunakan teknik Electroencephalography(EEG) untuk membaca listrik yang mengalir akibat bekerjanya otak manusia. Listrik pada otak manusia, memiliki amplitude yang sangat kecil, dengan perangkat ini, gelombang tersebut akan diperbesar sehingga dapat dilihat respon di setiap aktifitas manusia.

Pada penelitian ini dataset yang diperoleh menggunakan sensor otak EEG dengan jumlah kanal sebanyak 14 buah elektroda untuk mendeteksi beberapa lokasi permukaan kulit dibagian kepala. Dataset yang diperoleh berupa data luaran ADC dari setiap elektroda, sehingga untuk satu kali pembacaan aktifitas mata akan memiliki 14 buah data. Kemudian data tersebut diolah dengan menggunakan metode K-Nearest Neighbour dengan dua teknik pengolahan data dimana pada KNN \#1 merujuk pada teknik pengolahan yang sudah banyak digunakan, sedangkan pada KNN \#2 merupakan teknik pengolahan data dengan modifikasi pada euclidean distance nya.

\section{Tinjauan Pustaka}

Peneliti yang melakukan penelitian tentang hubungan antara gelombang otak dengan aktifitas manusia ini pun berasal dari berbagai bidang, yaitu engineering, artificial intelligence, kedokteran dan scientist[9]. Penelitian dari bidang engineering meliputi pembahasan tentang elektroda yang digunakan di EEG seperti pada [1] membahas tentang penggunaan elektroda yang diletakan pada telinga, keunggulan pada paper[1] ini adalah elektroda yang digunakan berupa elektroda kering, dimana pada penelitian lain harus menggunakan elektroda yang basah untuk konduktivitas yang lebih baik. Pada [2] membandingkan tentang teknologi elektroda untuk akuisisi EEG secara portable, selain itu pada [2] memperkenalkan sebuah low cost dan elektroda yang digunakan untuk mendeteksi gelombang otak bayi yang baru lahir dengan bentuk elektroda yang ringkas dan minim persiapan pemasangan elektroda sebelum merekam.

Sedangkan penelitian pada bidang kecerdasan buatan meliputi bagaimanan mengenali sinyal yang dihasilkan oleh sensor otak. Sebagai contoh pada [3] menerapkan metode KNN dengan teknik relative power ratio untuk mendeteksi Acute Ischemic Stroke Group Level. Kemudian pada [4] mengajukan teknik prediktor baru yang mengkombinasikan common spatial pattern (CSP) dan long short-term memory (LSTM) network untuk meningkatkan performa klasifikasi motor Imagery (MI) pada EEG. Pada EEG dapat dibagi menjadi beberapa jenis gelombang berdasarkan frekunsinya yaitu Alpha, Betha, dan Theta dan Delta. gelombang ini memiliki fungsi tersendiri dalam menerjemahkan aktifitas manusia. Gelombang Alpha memiliki rentang 
frekuensi antara 7.5 - $13 \mathrm{~Hz}$. Gelombang alpha muncul ketika aktifitas manusia dalam kondisi rileks dan menutup mata dan gelombang ini akan hilang ketika membuka mata atau beraktifitas fisik lainnya. Pada gelombang Betha yang berada pada frekuensi lebih besar dari $14 \mathrm{~Hz}$ dan gelombang beta hadir ketika membuka mata dan aktifitas lainnya. Gelombang Delta memiliki frekuensi dibawah $3 \mathrm{hz}$ oleh karenanya biasa disebut sebagai frekuensi terlambat tetapi memiliki maginitude terbesar. Gelombang delta biasa nya hadir ketika tidur.Gelombang Theta memiliki gelombang dengan range 3.5-7.5 Hz, gelombang ini normal hadir pada anak-anak hingga usia 13 tahun ketika tidur. Pada penelitian [5] melakukan penelitian tentang klasifikasi sinyal alpha dan beta pada pasien stroke.

\section{Metode Penelitian}

Adapun metode yang akan digunakan pada paper ini adalah metode K-Nearest Neighbour, metode ini sangat mudah digunakan karena rumus yang digunakan hanya rumus sederhana yaitu kuadrat, pengurangan dan akar. K-Nearest Neighbour atau dapat juga dipanggil sebagai K-Mean Algorithm merupakan algorithm yang menghitung akar kuadrat (euclidean distance) dari selisih antara nilai sample dengan nilai uji, nilai yang terkecil merupakan solusi dari permasalahan. Euclidean Distance Metode K nearest neighbour dinyatakan pada persamaan (1).

$$
d=\sqrt{(\text { sample_value-test_value })^{2}}
$$

Pada paper ini akan digunakan dua buah metode K-Nearest Neighbour dengan dua buah penggunaan pencarian euclidean distance yang berbeda[10]. Hal ini dikarenakan data input yang merupakan data sensor otak memiliki 14 kanal masukan, sehingga diperlukan formulasi yang tepat untuk dapat mengklasifikasikan input. Berikut adalah cuplikan data dari sensor EEG berdasarkan [6] yang dinyatakan pada tabel berikut ini:

\begin{tabular}{|c|c|c|c|c|c|c|c|c|c|c|c|c|c|c|}
\hline $\begin{array}{l}\text { Ch1 } \\
\text { AF3 }\end{array}$ & $\begin{array}{l}\text { Ch2 } \\
\text { F7 }\end{array}$ & $\begin{array}{l}\text { Ch3 } \\
\text { F3 }\end{array}$ & $\begin{array}{l}\text { Ch4 } \\
\text { FC5 }\end{array}$ & $\begin{array}{l}\text { Ch5 } \\
\text { T7 }\end{array}$ & $\begin{array}{l}\text { Ch6 } \\
\text { P7 }\end{array}$ & $\begin{array}{l}\text { Ch7 } \\
01\end{array}$ & $\begin{array}{l}\text { Ch8 } \\
\mathbf{O 2}\end{array}$ & $\begin{array}{l}\text { Ch9 } \\
\text { P8 }\end{array}$ & $\begin{array}{l}\text { Ch10 } \\
\text { T8 }\end{array}$ & $\begin{array}{l}\text { Ch11 } \\
\text { FC6 }\end{array}$ & $\begin{array}{l}\text { Ch12 } \\
\text { F4 }\end{array}$ & $\begin{array}{l}\text { Ch13 } \\
\text { F8 }\end{array}$ & $\begin{array}{l}\text { Ch14 } \\
\text { AF4 }\end{array}$ & Kedipan \\
\hline 4314 & 4008 & 4268 & 4128 & 4335 & 4584 & 4092 & 4625 & 4212 & 4231 & 4210 & 4275 & 4624 & 4382 & 0 \\
\hline 4291 & 4002 & 4266 & 4107 & 4331 & 4611 & 4088 & 4620 & 4202 & 4217 & 4197 & 4282 & 4590 & 4355 & 1 \\
\hline
\end{tabular}

Tabel 1. Dataset luaran EEG [6]

Pada tabel 1 diatas, ada 14 data dan 1 buah label 'kedipan', label kedipan mata bernilai 0 menyatakan mata terbuka dan 1 menyatakan mata berkedip, atau dapat dikatakan 0 dan 1 merupakan aktifitas kedipan mata manusia. Sedangkan 14 buah data terdiri dari Ch1-Ch14 diperoleh dengan menggunakan 14 kanal emotiv brainsensor seperti yang ditunjukan pada gambar 2 .

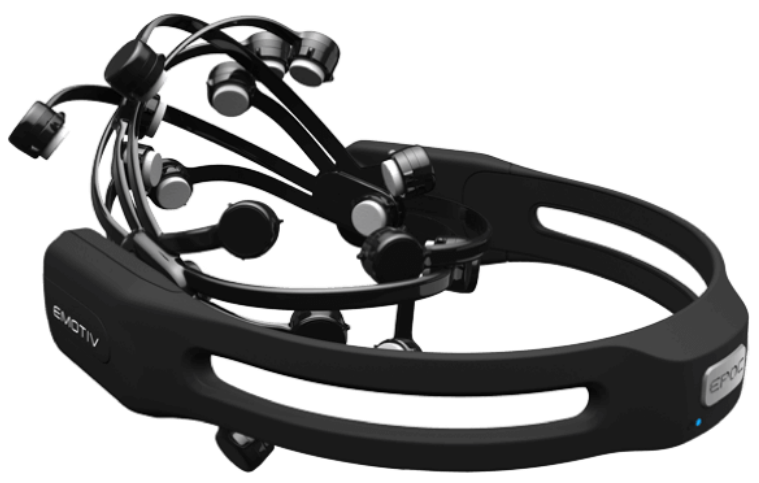

Gambar 1. Emotiv 14 Kanal Brain Sensor

Pada brain sensor setiap kanal diukur dengan elektroda yang diletakan dibagian kepala, setiap elektroda akan mengukur besaran tegangan yang dihasilkan oleh aktivitas otak manusia dalam tegangan microvolt, kemudian hasil tegangan tersebut akan diamplifikasi agar menjadi tegangan yang dapat dibaca oleh ADC. Adapun nilai yang diperoleh kemudian dinyatakan pada tabel 1. Penempatan elektroda disetiap bagian kepala 
dinyatakan pada gambar 2 .

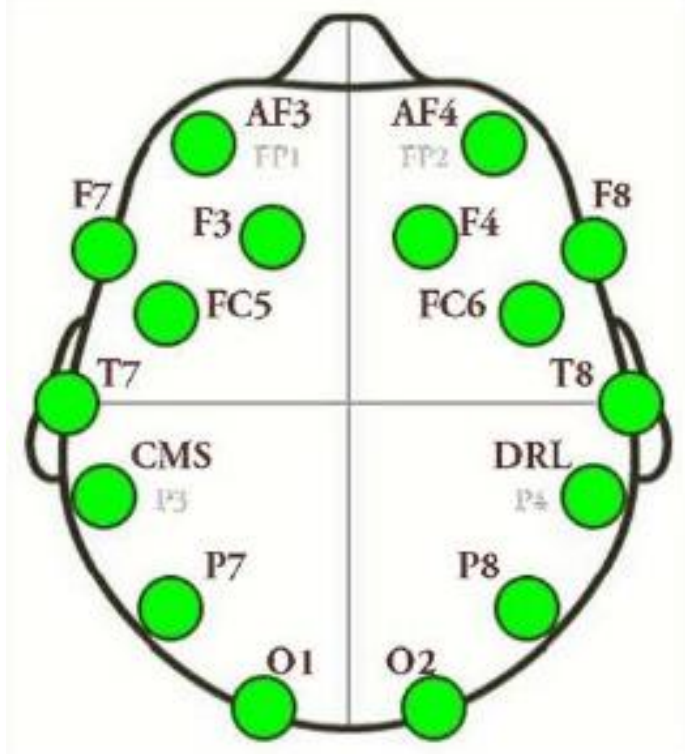

Gambar 2. Peta posisi Elektroda EEG pada kepala

$$
d=\sqrt{\left(\sum_{c h=1}^{14}\left(d b_{c h}-\text { test }_{c h}\right)^{2}\right)}
$$

(2)

result $=$ index_of $(\min (d))$

kemudian pada metode KNN \#2, yaitu dengan teknik menjumlahkan terlebih dahulu setiap kanal kemudian dikuadratkan(untuk menghindari akar negatif) dan diakarkan. Seperti yang dinyatakan pada persamaan (3) berikut

$$
d=\sqrt{\left(\sum_{c h=1}^{14}\left(d b_{c h}\right)-\sum_{c h=1}^{14}\left(\text { test }_{c h}\right)\right)^{2}}
$$

(3)

result $=$ index_of $(\min (d))$

Hasil akhir yang diperoleh dari persamaan (2) dan (3) akan bernilai 0 atau 1 yang menyatakan status mata berkedip atau tidak berkedip. Index_of merupakan pencarian nomor database manakah yang digunakan dan memiliki nilai terkecil tersebut.

Kedua metode tersebut akan dibandingkan untuk dilihat metode yang mana yang lebih baik dalam mengklasifikasikan nilai uji sehingga dapat diterapkan untuk memprediksi status mata apakah berkedip atau tidak berkedip dengan menggunakan luaran dari 14 kanal brain sensor.

\section{Hasil dan Pembahasan}

Pengujian dilakukan untuk melihat teknik pengolahan data dengan metode KNN mana yang lebih efektif dalam mengklasifikasikan luaran gelombang otak dalam mendeteksi kedipan mata. Dataset yang digunakan diperoleh dari [6] yang terdiri dari 14 kanal luaran emotiv.

Pada paper ini KNN dengan menggunakan dua teknik dikarenakan input yang diberikan lebih dari satu atau 14 input, sehingga teknik pengolahan data input akan sangat penting. Pada KNN \#1 formulasi yang digunakan merupakan formulasi yang umum digunakan untuk menghitung input lebih dari 1 yaitu dengan cara mengurangkan setiap input dengan kanal yang sama lalu dikuadratkan kemudian menjumlahkannya dan diakarkan. Sedangkan pada KNN \#2 yaitu dilakukan penjumlahan terlebih dahulu setiap kanal, dicari selisih nya, kemudian dikuadratkan lalu diakarkan. Hasil percobaan perbandingan kedua teknik KNN yang diperoleh melalui simulasi komputer ditampilkan pada tabel 2 berikut ini : 


\begin{tabular}{|c|c|c|}
\hline TRIAL & KNN \#1 & KNN \#2 \\
\hline $\mathbf{1}$ & $36 \%$ & $80 \%$ \\
\hline $\mathbf{2}$ & $35 \%$ & $72 \%$ \\
\hline $\mathbf{3}$ & $32 \%$ & $69 \%$ \\
\hline
\end{tabular}

Tabel 2. Akurasi dari metode KNN \#1 and KNN \#2

Dari table 2 dapat dilihat perbandingan akurasi dari ke 2 teknik pengolahan data pada metode KNN. Hasil pengujian dilakukan dengan mengambil 10.000 dataset sebagai data sampel(database) dan untuk data uji digunakan 100 sample setiap trialnya. Dari tabel dapat dilihat hasil dengan menggunakan KNN \#1 yang dilakukan dalam 3 kali trial yaitu dengan akurasi rata-rata 34\%, hasil ini tergolong cukup rendah untuk digunakan untuk memprediksi. Sedangkan pada metode KNN \#2 dapat dilihat akurasi yang diperoleh cukup besar yaitu dengan akurasi rata-rata 73\%. Hal ini cukup untuk digunakan sebagai metode klasifikasi untuk mengidentifikasi luaran gelombang otak dalam mendeteksi kedipan mata manusia. Pengujian selanjutnya yaitu untuk melihat kecepatan sistem dalam mengidentifikasi dengan jumlah database yang terus ditambah. Hasil pengujian ditunjuka pada tabel 3 .

\begin{tabular}{|c|c|c|}
\hline $\begin{array}{c}\text { JUMLAH } \\
\text { DATASET }\end{array}$ & $\begin{array}{c}\text { KNN \#1 } \\
\text { (S) }\end{array}$ & $\begin{array}{c}\text { KNN \#2 } \\
\text { (s) }\end{array}$ \\
\hline $\mathbf{1 0 0}$ & 0.0005 & 0.0004 \\
\hline $\mathbf{1 . 0 0 0}$ & 0.0211 & 0.0153 \\
\hline $\mathbf{5 . 0 0 0}$ & 0.7651 & 0.3931 \\
\hline $\mathbf{1 0 . 0 0 0}$ & 2.1342 & 1.0568 \\
\hline
\end{tabular}

Table 2. Rata-rata lama waktu klasifikasi

Dari hasil yang diperoleh pada tabel 2 dapat dilihat perbandingan performansi kedua metode jika ditambahkan jumlah database. Hal ini penting karena jumlah sampel yang digunakan akan sangat mempengaruhi akurasi dan kecepatan pengklasifikasian, karena untuk menguji akan dilakukan pencarian selisih pada seluruh sampel yang digunakan. Pada tabel diuji 100 sampel hingga 10.000 sampel dan pada metode KNN \#1 metode yang digunakan menunjukan performansi mendekati 50\% lebih lambat dibandingkan dengan metode KNN \#2.

\section{Kesimpulan}

Makalah ini menyajikan teknik dalam KNN untuk mengklasifikasikan input dari sensor gelombang otak. Teknik pengolahan data dengan metode KNN yang digunakan dibagi menjadi dua jenis yaitu teknik KNN \#1 yang merupakan teknik yang umum digunakan dan KNN \#2 adalah teknik penyesuaian yang diusulkan dalam makalah ini. Kedua teknik diuji dan dibandingkan dalam kinerja.

Dari hasil analisis, diperoleh bahwa KNN \#1 dan KNN \#2 memiliki kemampuan untuk mengenali data sensor otak, tetapi masih ada kegagalan dalam pengenalan dan waktu eksekusi masih sekitar 1 detik jika data yang terlatih lebih dari 5.000. Dari hasil terlihat bahwa KNN \#2 memiliki kinerja yang lebih baik daripada KNN \#1. Dan waktu eksekusi dua kali lebih cepat dari KNN \#1.

Pemrosesan data dari sensor gelombang otak ini bertujuan untuk menciptakan sistem yang dapat digunakan dalam realitas virtual. Tetapi untuk kontrol realitas virtual, metode ini masih perlu ditingkatkan untuk mendapatkan kinerja yang lebih baik dalam kontrol Virtual Reality.

\section{Acknowledgments}

Penelitian ini didanai dari Hibah ITERA Smart Mandiri Research 2019 No: B/324/IT9.C1/PT.01.03/2019.

\section{Daftar Pustaka}

[1] S. L. Kappel, M. L. Rank, H. O. Toft, M. Andersen and P. Kidmose, "Dry-Contact Electrode EarEEG," in IEEE Transactions on Biomedical Engineering, vol. 66, no. 1, pp. 150-158, Jan. 2019.

[2] M. O'Sullivan, J. P. Pena, A. Bocchino, C. O'Mahony, D. Costello, E. Popovici and A. Temko, "Comparison of electrode technologies for dry and portable EEG acquisition," in 2017 7th IEEE International Workshop on Advances in Sensors and Interfaces (IWASI), Vieste, Italy , 2017 .

[3] W. R. W. Omar, N. Fuad, M. N. Taib, R. Jailani, R. M. Isa, Z. Mohamad and Z. Sharif, "Brainwave Classification for Acute Ischemic Stroke Group Level Using k-NN Technique," in 2014 th International Conference on Intelligent Systems, Modelling and Simulation, Langkawi, Malaysia, 2014. 
[4] S. Kumar, A. Sharma and T. Tsunoda, "Brain wave classification using long short-term memory network based OPTICAL predictor,” Naturesearch, 2019.

[5] B. S. Zainuddin, H. Zakaria and I. s. Isa, "Alpha and beta EEG brainwave signal classification technique: A conceptual study," 2014 IEEE 10th International Colloquium on Signal Processing \& its Applications (CSPA), 2014.

[6] O. Roesler, "EEG eye State Dataset," [Online]. Available: https://archive.ics.uci.edu/ml/datasets/EEG+Eye+State. [Accessed 507 2019].

[7] J. Gwizdka, R. Hosseini, M. Cole and S. Wang, "Temporal dynamics of eye-tracking and EEG during reading and relevance decisions," Journal of the Association for Information Science and Technology, p. 68, 2017.

[8] M. Sun, W. Jia, W. Liang and R. J. Sclabassi, "A low-impedance, skin-grabbing, and gel-free EEG electrode," in 2012 Annual International Conference of the IEEE Engineering in Medicine and Biology Society, San Diego, CA, USA, 2012.

[9] S. Syukri and S. Samsuddin, "Pengujian Algoritma Artificial Neural Network (ANN) Untuk Prediksi Kecepatan Angin," J. Nas. Komputasi dan Teknol. Inf., vol. 2, no. 1, pp. 43-47, 2019.

[10] F. Arnia and R. Muharar, "Deteksi Pemalsuan Citra dengan Teknik Copy-Move Menggunakan Metode Ordinal Measure dari Koefisien Discrete Cosine Transform,” J. Nas. Tek. Elektro, vol. 5, no. 2, pp. 165-174, 2016. 